clusions on the subject, that "berries obnoxious to birds will stand a better chance of propagating and increasing that variety?" If C. W. W. (NATURE, July 7) will turn to Letter 55 of White's "Selborne" he will find the following observation on the House Martin :-..' The young of this species do not quit their abodes all together, but the more forward birds get abroad some days before the rest. These approaching the eaves of buildings and playing out before them make people think that several oid ones attend one nest."

\section{Our Middle-Class Schools}

I WISH to bring before your readers the necessity of immediate action with regard to a branch of education at present not liable to legislative interference. Government is becoming more and more alive to the fact that Education and Science at the present are England's greatest needs; hence the steps taken to extend and enforce primary education. But whilst increased facilities are being afforded to raise the standard of primary education, secondary education is at a stand-still, and upon the whole falls far short of the point it should reach. Thousands of our middleclass schools when compared with what is required, may be placed in the same category as the old dame's school when compared with the modern national school. It requires but the slightest knowledge of the subject to know that our middle-class educational system is as a whole a mere farce, and yet so averse are we to change, that matters are allowed to go on year after year in the same old matter-of-course style without the slightest indication of reform. In order to encroach upon your space as little as possible, I will in a succinct and concise form lay before your readers a scheme which has been lately mooted, which has received the sanction of the highest authorities in these matters, and which is destined ultimately to bring about quite a new system. ${ }^{*}$ In speaking thus indiscriminately of our middle.class schools, I do not include many excellent institutions, in which a thorough course of training forms the rontine, and which are conducted by gentlemen capable and willing to do the work required. Alas that there should be so few!

Then Ist. It is well known that individual influence is of little service. This fact supports the theory that an association must be formed, consisting of the principals and assistants of middleclass schools, and others interested in the question.

2nd. This society should have certain objects, and its members combined should use their utmost endeavours to assist in carrying out these objects. A few of the aims would be as follows :-

a. The institution of normal colleges for the training of gentlemen who wish to enter the scholastic profession.

B. To recognise some examination, diploma, \&c., as sufficient guarantee of the capabilities of $\mathrm{g}$ entlemen entering the profession, and insist that such gentlemen shall have this diploma. The evils arising from the incapability of so many of our masters cannot be over-estimated.

$\gamma$. The necessity of Government or other central supervision and examination of evcry school. At the present moment the standard of a school is calculated by nothing. An advertisement perhaps appears, stating that $a l l$ boys sent to special examinations have passed; and instances are known where one boy has been sent up to such examination. It is impossible to decide upon the general tone of a school by the examination of a fere of the best boys.

$\delta$. The institution of a club-house in London where appointments could be made, business transacted, \&c., and attached to it some means by which the incubus of agents could be avoided.

€. Periodical meetings, \&c., \&c.

I am afraid this letter is running to an inordinate length, but I just wish to add that invitations have been issued by the editor of the Quarterly fournal of Education to a few representative gentlemen for a private preliminary meeting to be held in September next, when the above scheme is to be discussed. Any gentleman wishing to take part in that meeting should address the editor upon the subject. I might have referred to the failure of the College of Preceptors to do the least good. What we must have is an obligatory examination of the whole school, and every school; not leaving it to the whim of the principals. Neither are assistant masters treated as they should be by the College of Preceptors.
The Source of Solar Energy

Mr. Greg ascribes to me views I do not hold, and then employs my own reasoning to overthrow them. He must have formed his conceptions of my theories from Prof. Pritchard's critique of my "Other Worlds"--a nost unreliable source.

To begin with,-I do not believe that the solar heat supply is solely derived from the downfall of meteors. I have im. pressed this very clearly at p. 54 of my "Other Worlds."

I do not believe that any part zuhaterer of the solar heat supply is derived from meteoric percussion, nor that any meteor ever comes within tens of thousands of miles of the sun's surface in the solid state.

Mr. Greg is very careful to show me that the meteor-systems encountered by the earth cannot fall into the sun. I dwell on this very fact at p. 203 of "Other Worlds"-I say, totictem verbis, that no known meteoric system can form a hail of meteors upon the sun. "It is forgotten," says Mr. Greg, "that the meteors themselves revolve round the sun," \&c. If he has at any time forgotten this, I certainly have not.

"Has it ever been proved," he asks me, "that the entire mass of meteors constituting the zodiacal light, is either composed of matter in a solid state, or, if it were, that its mass would be equal to that of our own earth?" I answer, as $\mathrm{Mr}$. Greg would-." "No, it has not been proved, nor is it by any means probable."

There is nothing new to me in Mr. Greg's letter, and little which I have not described myself long ago in the Intellectzcal Observer and Student of 1867,1868 , and 1869 . To suppose that I should venture to treat at all of meteoric astronomy, in ignorance of such elementary facts-the very A B C of the science-is not complimentary. Mr. Greg might, at least, have examined what I have written before assigning to me the $a b$. surdities he attacks so successfully.

The fact is, this matter of the solar energy only comes in par parenthèse in my "Other Worlds." I express no confident opinion whatever about it. I point to some deductions from known facts, and respecting then express a certain feeling of confidence. It is not my fault (nor, indeed, can I blame $\mathrm{Mr}$. Greg) if Prof. Pritchard has tacked my words "I am certain" (used with reference to reliable inferences) to a theory respecting which I have distinctly written, that "I should not care positively to assert" its truth. Even that theory is not the absurd one attacked (very properly) by Mr. Greg.

For the rest, most of Mr. Greg's letter is sufficiently accurate, but there are two mistakes in it.

I. We have abundant evidence that the density of the aggregation of cometic perihelia increases rapidly near the sun For example, whereas between limits of distance $40,000,000$ and $60,000,000$ miles from the sun this density is represented by the number $x \cdot 06$, it is represented by the number 1.67 for limits $20,000,000$ and $40,000,000$ miles, and by the number 8.65 within the distance $20,000,000$ miles. The evidence derived from this observed increase of aggregation is not affected by what wre know of those cometic or meteoric systems whose orbits nearly intersect the earth's (for they must form but the minutest fraction of the total number) nor by the observed minimum perihelion distance of cometic orbits (for observed comets are but the minutest fraction of the total number).

2. It makes no difference whatever as regards the forcesupply of the solar system, whether the substance of a meteor reaches the sun in the solid, fluid, or vaporous state. Given that the substance of a meteor, moving at one time with a certain velocity at a certain distance from the sun, is at another time (after whatever processes) brought to rest upon or within the sun's substance, then either the "force-equivalent" of its motion has been already distributed or the substance of the meteor is in a condition to distribute that "force-equivalent" mediately or directly. In other words, either heat and light have been already distributed, or the central energy has been recruited to the full extent corresponding to the mass, motion, and original distance of the meteor.

I may express here my agreement with the opinion of the Editor of NATURE that the observations made on the zodiacal light by Lieut. Jones and M. Liais ought to be taken into account in any theory of that mysterious object. Taken in conjunction with the other known phenomena of the zodiacal light, they admit of but one interpretation as to the positicn, dimensions, and general characteristics of the object. Taken alone, we might infer from them that the zodiacal light is a ring of bodies or vapours travelling around the earth (at a considerable distance); 